\title{
A New Exploration into the Innovative Development of Old Care Service in Shandong under the Mode of Combination of Medical and Health Care
}

\author{
$\mathrm{Na} \mathrm{Han}$ \\ School of Economic and Management \\ Zaozhuang University \\ Zaozhuang, China 277100
}

\author{
Kai Wang \\ School of Economic and Management \\ Zaozhuang University \\ Zaozhuang, China 277100
}

\begin{abstract}
Combining the general trend of "combination of medical and health care", this paper carries out all-around research work by taking analysis of the development plight of the pension service industry as the main purpose and pension service agencies in Shandong Province as the main research object through literature research, questionnaire surveys and key interviews. At the same time, some existing problems in the development of pension service industry in Shandong Province are pointed out with reference to the existing literature and the related data analysis, and the innovative development path of pension service industry is explored.
\end{abstract}

Keywords - combination of medical and health care; old-age service industry; innovation; Shandong province

\section{INTRODUCTION}

With the gradual aggravation of population aging, the issue of old-age care has become a hot issue that is generally concerned by all sectors of society. With the changes in the social and demographic structure, the traditional family supporting model has been seriously challenged. At present, the issue of old-age care has become a prominent problem of social livelihood.

\section{A. The Deep Development of Population Aging}

The aged population in China is huge and develops very rapidly. Data show that as of the end of 2013, the aged population over 60 in China has reached 200 million and is growing at an annual average rate of about 3\%. [1] The growth rate of advanced aging of the elderly in China is much faster rate than the aging of the elderly [2]. The physical quality of advanced ages is poor, and the incidence of chronic diseases and sudden illness is high. Elderly people who are semi-self-care and unable to take care of themselves are very common in the advanced ages, which poses a high requirement for the provision of medical resources.

\section{B. Miniaturization of Family Structure}

At present, the population size and the social structure have drastically changed. The family size tends to be miniaturized, the number of empty-nest families has been increasing and social mobility has been enhanced, so most children cannot stay with their parents for a long time, resulting in an increased incidence of chronic diseases. The issue of pension is more and more diversified, so the traditional community elder security cannot fully meet the diversification and high standardization of pension demand in the new situation.

\section{The Elderly are Important Targets for Health Care Services}

According to relevant data, the prevalence rate of chronic diseases of the elderly over 60 is about 3.2 times the prevalence rate of population in China, and the disability rate is about 3.6 times of that of the entire population. The health resources consumed by the elderly are 1.9 times the average consumption of health resources by all the population [3].

\section{LITERATURE REVIEW}

\section{A. The Concept of Elderly Care Services}

Elderly care work is a huge and complicated social system project, which requires the cooperation of government, society and public institution. In a narrow sense, old care service should be able to meet the material and spiritual needs of the elderly and provide them with the necessary living services [4]. In a broad sense, old care service is a big concept. This service concept can be described as the service that meets all the needs of the elderly, including the basic necessities of life, medical services, culture and entertainment and other fields [4].

\section{B. Classification of Old Care Service Agency}

1) Home-based care: Some scholars divide home-based care into three ways of "self-service", "others service" and "self + others service". The elderly can do whatever they can under the circumstances where they can take care of themselves, and they can also choose care services and health care and other services based on their needs.

2) Community care: With the continuous improvement of social security system, community care has also become a major feature of old care in China. Community care can hold elderly dance competitions, chess and other activities 
in the community as well as carry out the elderly continuing education activities.

3) Institution old care: There are many types of institution old care, among which the private old care institution are short of equipment and resource services, so it cannot provide the aged with an appropriate old care environment. On the contrary, public old care institutions, private-run public and private-funded old care institutions can meet the various needs of the elderly with wellequipped facilities [5].

\section{INVESTIGATION AND ANALYSIS}

The survey sends totally 300 questionnaires, and gets 282 back, including 4 invalid, with a total of 278 valid questionnaires. Among them, in-depth interviews are conducted with 15 staff members of the old care institution.

\section{A. Hardware Facilities of Old Care Institutions}

\section{1) Living pattern and costs}

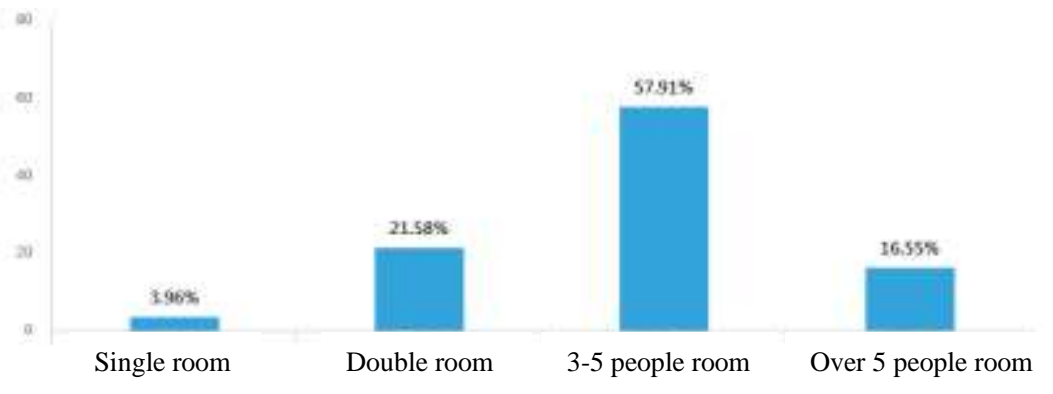

Fig. 1. Percentage of living patterns in old care institutions.

Older people choose different types of old care institutions, so there are big differences in the living pattern of old care institutions and charging standards. The elderly can choose based on comprehensive consideration of various factors according to their own actual situation. Private old care institutions are only equipped with simple beds, and even several elderly live together, without a single room. The facilities are simple and the corresponding fee is cheaper as shown in "Fig. 1".

2) Health institutions and health care support equipment

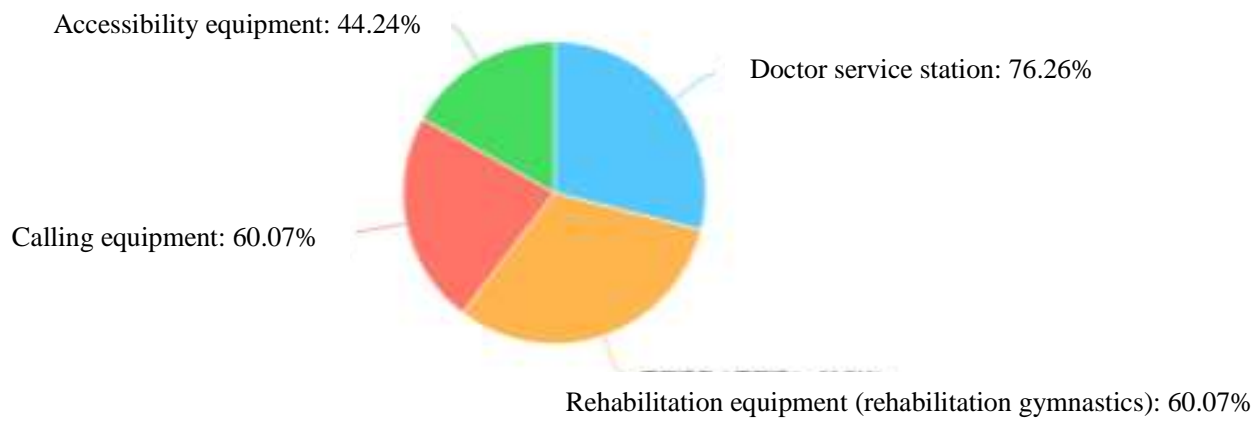

Fig. 2. Health care support equipment.

The old care institutions combining Medical and health care have mature professional medical care services and perfect management, which is mainly, aimed at home care, unattended elderly or those who are unable to take care of themselves. At the same time, facilities such as accessibility, rehabilitation and doctor service stations are set up according to the needs of the elderly. However, the survey finds that only the some formal and larger old care institutions are equipped with the corresponding facilities while private institutions cannot be equipped as shown in "Fig. 2".

\section{3) Medical facility}

It is found in the survey that more than half of the old care institutions are not equipped with complete basic medical facilities and the old care institutions built based on hospitals and old care institutions of hospitals relying on old care institutions are well equipped with medical resources and have professional medical care department, so that the elderly can get timely medical treatment if they encounter unexpected situations. Community care institutions are only equipped with a single medical service equipment.

\section{B. Software Facilities of Old Care Institutions}

\section{1) Basic services}

Old care institutions can provide the elderly with custom nutritious food paying attention to health. They are equipped with professional nurses and care workers. Besides, they provide psychological counseling services for the elderly who can take care of themselves, and provide meal delivery, laundry, changing clothes service extra for semi-self-cared elderly. For disabled elderly people, the services of turning over, bath, haircut, and feeding are provided. 


\section{2) Medical services}

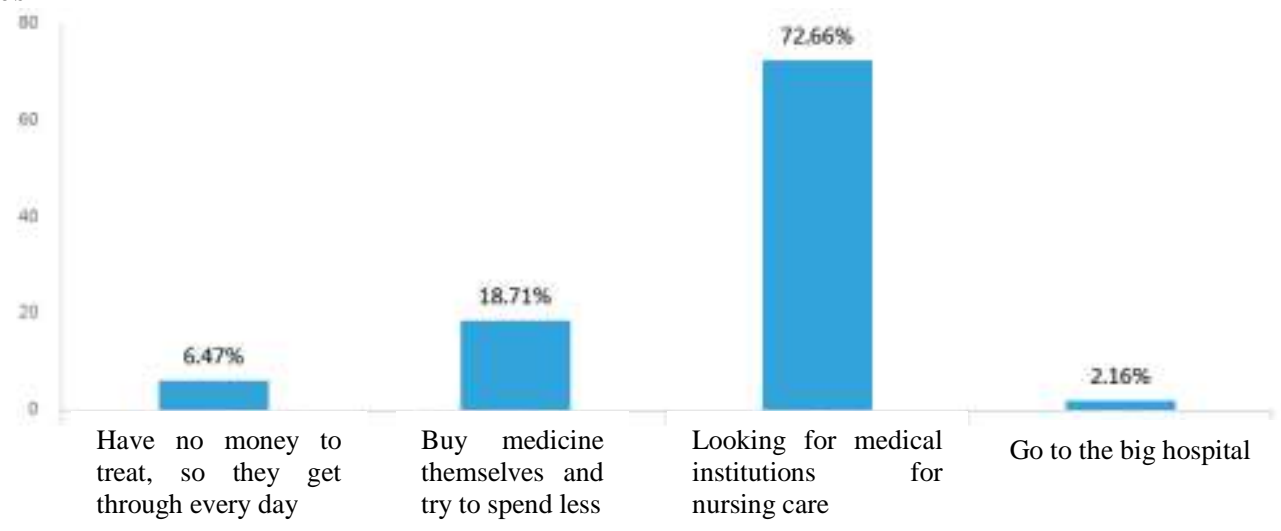

Fig. 3. Histogram of medical services.

The survey finds that private old care institutions are lack in the nursing services [6]. Community old care institutions have simple clinics that provide basic treatment for the elderly. The group and the public old care institutions have well-established hospitals combined with old care institutions to provide professional care and treatment for the elderly as shown in "Fig. 3".

3) Equipped care workers: More and more old care institutions have professional nursing staff, but privately-run ones can hardly meet the above conditions. In terms of choosing nursing staff, there is a big gap between private old care institutions and group and government support ones. The old care institutions should pay attention to the treatment of staff members and continuously improve the skills of professional training services so as to enhance the staff's cultural level and professional qualities.

\section{MAIN PROBLEMS IN THE INNOVATIVE DEVELOPMENT OF OLD CARE SERVICE INSTITUTIONS IN SHANDONG PROVINCE}

\section{A. The Elderly Lack the Knowledge of the New Type of Old Care}

Most old people's understanding of old-age care still stays in the traditional concept of "raising children for oldage". In today's society, if children send elderly people into old-age care service institutions or the elderly have no choice but to enter old care institutions, others will think their children unfilial. In addition, as old people think that spending money on the old care services is a waste of money, so they cannot accept new types of old care. As a result, they prefer to live alone at home rather than go to old care institutions.

\section{B. The Development of Advanced Aging Proposes High Requirements for Medical Treatment}

With the accelerating advanced aging, the advanced aging of aged population, and the increasing incidence of chronic diseases, more and more elderly people are unable to take care of themselves, which all put forward higher requirements on the allocation of medical resources.
Therefore, the continuous development and improvement of old care institutions combining medical with health care can meet the ever-increasing requirements of advanced aging.

\section{Poor Quality of Service, Single Species, and the Lack of Recreational Activities}

The current old care service agencies should not only meet the various needs of the elderly in body care, but also make them feel happy psychologically and mentally. However, judging from the current development status of old care services in Shandong Province, most old care service agencies only focus on ensuring the daily basic needs of the elderly.

\section{Insufficient Nursing Staff and Unprofessional Equipment}

At present, there are nearly 10 million gaps in the provision of nursing staff in the elderly in China. From the survey, it can be found that the issues of lack of training for professional talents and forward-looking planning for the development of qualified personnel and the nursing staff lacking professional training, formal training and the corresponding qualifications training for appointment are prominent.

\section{CONCLUSION}

Through the above investigation and analysis, the construction of innovative development path of old care institutions in Shandong Province can start from the following aspects:

First, the government should vigorously support the development of old care service industry and conduct publicity and education so that the public, especially the elderly will change their traditional concept of old-age care and accept the new-type old care service. In addition, we should establish a more mature and perfect old care system and speed up the reform of the medical insurance system.

Second, the support of various local governments should be increased and the targeted special fund input should be increased. Local governments need to speed up the construction of community old care service platform to 
encourage private capital to actively participate in the development of old care services and promote the development of old care services in the community.

Third, we should optimize the allocation of local medical resources more reasonably to strengthen its link with old care institutions. Part of the effective medical resources should be rationally allocated and elderly care homes and pension service centers should be set up combining with the medical resources of county-level hospitals and other institutions. At the same time, in order to truly realize the "combination of medical and health care" old care mode as soon as possible, we need to strengthen the close connection between local medical institutions and old care institutions.

Fourth, we should shape professional medical staff. We can conduct targeted training for professional service personnel to enhance professionalism and develop all-around health care professionals. We can carry out cooperation of industry-university-research with colleges and universities and establish senior care major in colleges and universities to carry out directed education to nursing staff or set up a professional network of nursing staff training in the community old care service agencies.

Fifth, we can promote the combination of artificial intelligence and old care services. We can let artificial intelligence to replace artificial pensions. For example, nanny robots can provide daily life care and real-time monitoring services for the elderly as well as interact with the elderly to provide the elderly life with pleasure. At the same time, "artificial intelligence" and "home-based retirement care" can be combined, and old care service agencies can establish a two-way communication mechanism with their families. The elderly can enjoy the resources of the old care institutions immediately even when they are at home.

\section{REFERENCES}

[1] Wu Xue. Effect of Population Aging on China's Economy [J]. Hebei Business, 2015 (5).

[2] Yuan Ye. The Socio-Economic Impacts of Imbalanced development of Population Aging and advanced Aging in China [C]. The Fifth National Census Scientific Symposium, 2003.

[3] Zeng Ping, Liu Xiaohong. Successful aging [J] Chinese Journal of Geriatrics, 2013, 32 (4).

[4] Tang Zhenxing. Considerations on developing the old care service industry in China [J] Scientific Research on Aging, 2014 (2).

[5] Xiong Haiqiang. Study on the policy support system of private pension institutions development [D] East China University of Political Science and Law, 2016

[6] Gu Jingxian. Exploration of long-term care service supply mechanism of the elderly [D] Zhejiang University of Finance and Economics, 2016.

[7] Chang Zhen. Study on the development of old care service industry in Hefei [D] Anhui Normal University, 2012.

[8] Feng Xiliang. Research Report on the Implementation Status of home-based Old-age Care Services in community - Based on Survey Data of Beijing in 2015 [R] Beijing, 2017-02-16.

[9] Gu Shengzu. strategic thinking on developing old care services to deal with the aging population [J] Economic Review, 2015 (9).
[10] Kang Rui. Reflections on the development of residential care industry - A case study of Hainan Province [J] China Social Welfare (Theory Version), 2016 (4).

[11] Li Limin, Zeng Feifan. Market Size and Industry Choice of Old care Services in Fujian Province [J] development research, 2016 (12)

[12] Liu Bo. Discussion on the Development of China's Rural Elderly Care Services under the New Urbanization [D] Sichuan University, 2015.

[13] Liu Xiaomei. Analysis on the Role of Social Organization in old care System under Diversified Perspectives [J] Social Security study, 2017 (2). 